\title{
QLUALITY OF LIFE OF CHRONIC KIDNEY DISEASE PATIENTS IN EGYPTIAN ENVIRONMENT
}

\author{
Ragab, M. H. ${ }^{(1)}$ Awad, M. I. ${ }^{(2)}$ and Habib, M. S. ${ }^{(3)}$ \\ 1) Institute of Environmental Studies and Research, Ain Shams University
}

\begin{abstract}
Intoudction: Chronic Kidney Disease (CKD) is a public health problem that tends to take dimensions of epidemic, has a profound and pervasive effect on patients resulting in psychological strain, social isolation and has serious impact on quality of patient's life and are important predictors of patients outcome
\end{abstract}

Aim of the Study: is to determine the effects of socio-demographic and clinical, characteristics of chronic kidney disease patients on their quality of life.

Subjects \& Methods: Cross sectional case control study were a sample of 60 patients with CKD (case group) aged 18-72 years from inpatient and outpatients clinic in nephrology department in Aokaf hospital, in addition to 40 control group of normal healthy subjects. Full history, clinical examination and lab investigations were done to all subjects. Also the subjects will be assessed for WHOQOL-BREF (WHO, 1996)

Results: This study has shown that the presence of adequate social support $(p=)$ were significantly associated with higher scores on WHOQOL-BREF domains while being divorced $(\mathrm{p}=)$, late stage of CKD $(\mathrm{p}=)$, presence of complications $(\mathrm{p}=)$, being on higher number of medication $(\mathrm{p}=)$ and being on a current treatment of $\operatorname{RRT}(\mathrm{p}=)$ were significantly associated with poor quality of life among CKD patients.

Comparing the QoL (all 4 domains) of patients and control group there was significant difference in all four domains were QoL showed lower scores in patients compared with control healthy group. The difference in physical domain was $\mathrm{p}<0.001$, psychological $\mathrm{p}<0.001$, social $\mathrm{p}<0.001$ and environmental $\mathrm{p}<0.001$ respectively

Conclusions: Socio-demographic and clinical factors influence the quality of life of chronic kidney disease patients. However, efforts made at early 
detection and treatment with provision of social \& psychological assistance may help reduce their negative effects on the quality of life of these patients.

\section{INTROUDCTION}

The attention being paid globally to chronic kidney disease is attributable to five factors; the rapid increase in its prevalence, the enormous cost of treatment, recent data indicating that overt disease is the tip of an iceberg of covert disease, an appreciation of its major role in increasing the risk of cardiovascular disease, and the discovery of effective measures to prevent its progression Barsoum RS 2002. Although the credibility of statistics from many developing countries may be questionable, the majority of experts agree that 150 per million populations is the average incidence of ESRD. Barsoum RS 2002

In chronic medical illnesses, at least two types of risk factors may effect survival; medical parameters and psychosocial strengths. Moos, et al. 1984The medical determinants of mortality in patients with chronic kidney disease are well appreciated, consisting of older age, presence of diabetes mellitus, and to a lesser extent, of co morbid conditions such as cardiovascular and cerebro-vascular disease, cancer, collagen vascular disease and chronic obstructive pulmonary disease Held et al 1994.

Psychosocial variables, such as extent of depression and social support, and patients' perceptions of their well-being, may also be related to outcome in patients with acute and chronic medical illness House, et al 1988, Such factors may affect compliance with treatment regimens Frasure-Smith et al 1999 
There is now a robust literature showing that depression is common in chronic kidney disease patients. Frasure-Smith et al 1999. The factors predisposing such patients to develop depression may include loss of vocational capacity; physical and functional effects of kidney failure and renal replacement therapy; large burden of somatic symptoms; and dependence on a chronic, life-sustaining treatment.

Early studies have, in fact, documented higher levels of pro inflammatory cytokines in chronic kidney patients with depressive effect and marital discord and established correlations between depression and mortality. House et al 1988. These intriguing findings underscore the need for a greater understanding of the burden and impact of psychosocial illness in patients with chronic kidney disease.

There is a substantial body of literature documenting the psychological impact and social burden of living with chronic disease. Depression and depressive affect, impairment in quality of life (QOL), disruptions in social support and vocational capacity, and somatic symptoms represent different manifestations of psychosocial distress. It is now clear that many such psychosocial processes are present in patients with chronic kidney disease (CKD). Bremer et al 1989

The impact of psychosocial factors on the outcome of patients with chronic kidney disease has been receiving more attention recently Finkelstein et al 1999. The progressive increase in both, the incidence and prevalence of patients with chronic kidney disease throughout the world, the high mortality rate and rising costs of providing care for those patients Finkelstein et al 1999 . 
Although the psychological and social difficulties experienced by patients maintained on dialysis have been noted -and commented on for some time, it has been only recently that researchers have begun to demonstrate that psychosocial factors are important predictors of patient outcome Levy et al 2002. For example, as the SF-36 Quality of Life and the Kidney Disease Quality of Life (KdQoL) questionnaires have become widely used, it is apparent that chronic kidney disease patients have higher scores on the emotional components of these assessments than controls, indicating, perhaps not surprisingly, that emotional difficulties are present in dialysis patients. However, what is particularly noteworthy is that scores on the emotional components of these questionnaires ate in fact strong predictors of patient outcome -Lowrie et al 1997. Thus, in the database of Fresenius Medical Care in the United States, Lowrie et al. have demonstrated that dialysis patients with scores lower than 51 on the Mental Component Scale of the SF-36 have progressively increasing risks of death. In fact, the patients with scores of 0 37 have twice the relative risk of death than those patients with scores of 51 or higher Lowrie et al 1997 ,

The psychosocial assessment of the patient with end-stage renal disease is critically important because there is growing evidence that the psychosocial status of the patient influences medical outcomes Kimmel et al2000 and the objective of therapy is to maximize a patient's sense of well-being and quality of life 


\section{AIM OF THE STUDY}

Is to determine the effects of socio-demographic and clinical characteristics of chronic kidney disease patients on their quality of life.

\section{SUBJECTS AND METHODS}

The study was conducted on sample of 60 patients (case group) aged 1872 years from inpatient and outpatients clinic in nephrology department in Aokaf hospital, during the period from 1-8-2014 to 30-6-2015. All patients complaining from chronic kidney disease proved by clinical examination and laboratory investigations.

A control group of 40 normal healthy individuals that match in socio economic state with case group was chosen.

Both group case and control will be subjected to:

\section{1- Full clinical history}

Including: Personal history including: age, sex, occupation, address, marital status, and special habits as smoking.

Complain: onset, course and duration

Present history

Past history

Family history: With emphasis on renal symptoms such as dysurea, hesitancy, frequency, incontinence of urine, lion pain.

\section{2- Full clinical examination}

General examination including: pulse, blood pressure, temperature, pallor, jaundice, cyanosis, radial pulsation, jugular venous pressure, clubbing, carotid pulsation, edema of lower limbs. 


\section{Specific examination including:}

Chest, heart, abdomen and neurological examination with special emphasis on renal system.

\section{3- Laboratory examination}

Including: Complete blood picture, complete urine and, urea, creatinine, Calcium, phosphorus and albumen level in serum.

II- Socioeconomic data will be collected for all subjects

\section{III- ALL the subjects will be assessed for Whoqol-Bref (Who, 1996)}

The WHOQOL-BREF (WHO, 1996) was used to assess the health related quality of life of respondents. This is a 26 item self-administered questionnaire. However, the questions were read out to illiterate patients by a trained research assistant and their responses recorded. Each item of the WHOQOL-BREF has five options which the patient is expected to respond to on a 5-point Liker-type scale. The WHOQOL-BREF produces a quality of life profile with four domain scores. (. Hays et al 1994).

The four domains are

1. Physical Health 2.Psychological Health

3. Social Relationship 4. Environment.

There are two items that are examined separately:

Question 1 asks about an individual's overall perception of quality of life and question 2 asks about an individual's overall perception of their health.

The physical health domain has 7 items; psychological health domain has 6 items; social relationship domain has 3 items while the environment domain contains 8 items. 
The four domain scores are scaled in a positive direction (i.e. higher scores denote higher quality of life). Three items: (items 3, $4 \& 26$ ) out of the 26 items are scaled in negative direction. The scores obtained on these items need to be recoded in order to transform them to positively framed questions. The range of raw scores that can be obtained on each domain are as follows; Domain 1: (7-35); Domain 2: (6-30); Domain 3: (3-15); Domain 4: (840).(Korevaar 2002)

The raw scores obtained on each domain were transformed into scores in the range between 0-100, with higher scores indicating better QOL.

The range of score that can be obtained from the 2 items examined separately (i.e. item 1: overall quality of life and item 2: health satisfaction) is between 1-5, with higher scores indicating better QOL.

The disease-specific component of the WHOQOL-BREF (WHO, 1996) which is KDQOL (short form) includes 44 questions, encompassing 43 kidney-disease targeted items and one overall health-rating question. Eleven domains, also on a 100-point scale, are measured with these questions, including (1) burden of kidney disease; (2) cognitive function; (3) dialysis staff encouragement; (4) effects of kidney disease; (5) patient satisfaction; (6) quality of social interaction; (7) sexual function; (8) sleep; (9) social support; (10) symptom problem; and (11) work status. The two questions relating to dialysis staff encouragement and patient satisfaction that are generally part of the disease-specific component of the KDQOL were excluded as they were not pertinent to the population under evaluation. (Samer et al, KDQoL- sf Arabic version, Rand 1994) 
Ethical consideration: Patients and controls gave verbal consent before inclusion. Patients who want to participate were asked to give consent to obtain patient characteristics from medical records. The study was approved by the ethical committees of the hospital. Complete confidentiality of any obtained information was ensured.

Statistical analysis Data entry and editing data will be entered on sheet of SPSS package (statistical package for social science). Chi- square and analysis of variance will be used to examine group differences.

Design of Study Cross sectional case control study

\section{RESULTS}

Socio demographic characteristics of patients, and controls were shown in table 1

The age of the patients group range from 18 years to 71 years (mean 45.8+9.3)-46 (76.6\%) patients was males and 14 (23.4\%) was females 15 (25\%) Were single or divorced while $45(75 \%)$ were married. $22(36.6 \%)$ Were employ while $38(63.4 \%)$ were unemployed. Patients with no or 1ry education were $39(65 \%)$ while those with high school or college degree were $21(35 \%)-34(56.6 \%)$ of patient felt they receive adequate social support from relatives while $2643.4 \%$ ) felt that social support was not adequate

The Sochi - demographic characteristics are similar in 2 study groups except for the age of patients group (35\% above 41 years) was more than control group (14\% above 41 years) and also the employment state in patient group (36.6\% employed) were less than control group (70\%).(table 1) 
In the study of The relation between overall KDQoL and sociodemographic characteristics of patients group (table2) no socio-demographic variables were statistically significant except that female patients showed statistically significant lower QoL $(\mathrm{p}<)$ than male patients.

However, in studying the relation of each domain of KDQoL separately with socio-demographic variables (table $3 \& 4$ ) we found that patients with age more than 60 years $(\mathrm{p}<0.001) \&$ presence of adequate social support $(\mathrm{p}<$ 0.004) were significantly associated with higher scores in environmental domain (table3). While single or divorced patients $(\mathrm{p}<0.003)$ or unemployed $(\mathrm{p}<0.07)$ had significantly poorer QoL scores (table 4$)$.

Table 5 shows the clinical characteristics of the patients group. 9 ( 11.6 $\%)$ Patients were at early stages of CKD (stage 1 or 2) while 51 ( $88.4 \%$ ) were in late stages (stag 3,4,or 5).

There was 38 ( $63.4 \%$ )-of patients with less than 5 medications per day while $22(36.6 \%)$ were on more than 5 medications per day.

Patients on renal replacement therapy were52 $(86.6 \%$-while those on conservative treatment were $8(13.4 \%$

Patients who had less than 3 co-morbidities' were37 (61.6\%)-while those with more than 3 co morbidity were 23(38.4\%)--egarding the effects of clinical variables of patients in their overall Qol (table 6), we found that being in late stage of $\operatorname{CKD}(\mathrm{p}<)$, presence of co-morbidity $(\mathrm{p}<0.01)$ and being on RRT ( $\mathrm{p}<0.03$ ) 0.019were significantly associated with poorer QoL (lower scores in overall QoL test). while no statistically significant difference ( $\mathrm{p}=$ 0.3 ) between QoL and number of medications taken by the patient. 
Comparing the QoL (all 4 domains) of patients and control group (table 7), there was statistically significant difference in all four domains (physical $\mathrm{p}<0.001$, psychological $\mathrm{p}<0.001$, social $\mathrm{p}<0.001$ and environmental $\mathrm{p}<$ 0.oo1) were QoL showed lower scores in patients compared with control healthy group.

\section{DIISCUSSION}

CKD has a serious impact on patients QoL ,decelerating his physical, psychological, social and environmental well being (Christensen et al 2002)

In developing countries - like Egypt -the main concern was merely on maintaining survival of patients, few - if any - studies was done evaluating the Qol of patients.

This study is to determine the effects of socio-demographic and clinical, characteristics of chronic kidney disease patients on their quality of life.

Males show better overall Qol $(p=0.003)$ than females in environmental domain (table 2), similar results found by Rocco et al 1997 \& Paniagua et al 2005

This may be explained by females are more vulnerable to chronic illness, this observation may need more attention from nephrologists.

We found that older patients (> 60 years) had higher scores (better QoL) $(p<0.001)$ in environmental domain of HRQOL than younger age group $(<$ 60 years).(table 4$)$

This was in agreement with Kimmel et al 1995 who found higher scores of satisfaction of life in older age 
This may be due to younger patients when discover their illness with CKD are more worried about their life expectation and their future than older patients

Single or divorced patients were associated with lower QoL than married patients in environmental domain (table 4) $(\mathrm{p}=0.06)$, this was related to lower QoL associated with lower social support seen in the same domain (environmental) (table 4) $(\mathrm{p}=0.04)$.

This is consistent with finding of Rambod et al 2010 who notice a better Qol is associated with adequate social support, this is reasonable since its known that good social support decrease the burden of chronic diseases.

Patients with no adequate social support were associated with poor QoL than patients who stated that they have adequate social support in environmental domain $(\mathrm{p}=0.04)$ (table 4). This is consistent with Classic social science witch asserts that social relationships affect an individual's well-being. It has been well established that patients with sparse social networks and low levels of social support have an increased risk for death.

This was also in agreement with Belasco AG, Sesso $R 2002$ who found that Social support, satisfaction with staff and adaptation to disease improve QoL resulting from chronic diseases.

No statistically significant difference in Qol between patients with higher level of education and those with lower education (table 5) $(\mathrm{p}=0.5)$. This was similar to Moreno et al 1996. However Condé et AL 2010 found that higher educational level were associated with better QoL 
The different result of this study from Condé et al 2010 may be due to smaller number of patients in this study and also higher educational level patients are more worried about their illness and aware with its complications.

The more sever is CKD the scores of QoL in physical, psychological and environmental domain will be statistically significant lower than less sever CKD (table 6) $(\mathrm{p}=0.006, \mathrm{p}=0.03 . \mathrm{p}=0.04$ respectively)

This s consistent with Rocco et al 1997 and to Mujais e al 2009 who found QoL is inversely proportional to severity of CKD.

This is understandable since the more sever CKD the physical deceleration will be more, which have adverse effects on psychological, social and environmental factors and vice versa.

Patients on more than 5 drugs medications per day showed lower QoL $(\mathrm{p}=0.001)$ than those who take less than 5 drugs per day in physical domain (table 6), this may be due to more drugs mean more co-morbidity of the patient which decelerate the QoL.

Also patients on dialysis treatment had lower QoL (table 6) than those on conservative treatment in physical and psychological domains. $(\mathrm{p}=0.001 \& \mathrm{p}=0.01)$

This was in agreement with Perlman et al 2005 and Kalender et al 2007 who found that haemodiaysis patients had lower Qol in sf-36 score than patients not on dialysis (Perlman et al 2005) and normal healthy controls (Kalender et al 2007).

The reasons mostly because haemodiaylsis patients being connected to dialysis machine 3 times per week, with strict diet control and exposed to 
complications during dialysis all expected to lower the patient QoL than nondialysis patients.

Patients with more Co-morbidities were associated with lower QoL than those with no co-morbidity (table 6) $(\mathrm{p}=)$. This is similar to Mujais et al 2009 who found lower QoL in patients with cardiovascular disease especially in physical domain of QoL.

The reason may be explained since co-morbidities detelorateing the physical health of the patients, this will decelerate his psychological and social state as well.

The Qol scores for patients group were lower in all four domains when compared to control group ( $\mathrm{p}<\mathrm{o}$, oo1) (table 7).

This result is in agreement with Sathvik et al 2009 who found the Qol of CKD patients was significantly impaired $(\mathrm{p}<0,005)$ when compared to healthy subjects especially in physical, psychological and social domains.

The reasons mostly due to CKD is usually associated with anemia, fatigue, appetite disorders which impair physical well being, which have adverse effects on psychological and social well being.

There is some limitations in this study, the small number of volunteers may need larger samples in the future, difficulties in finding patients in initial stages of disease as CKD is asymptomatic until $50 \%$ of renal function is lost, also many of asymptomatic CKD refuse to volunteer or neglect follow up visits. So most of patients subjects were in stage 4 and 5 of CKD, this has to be considered during evaluations of the results 
QoL questionnaire is highly subjective, the cultural and environmental factors should be considered when interpreting the answers. Also linguistics factors should be concederd since Arabic translated version of HRQoL only used in few studies.

\section{CONCLUSIONS \& RECOMMENDATIONS}

1- Socio-demographic and clinical factors influence the quality of life of chronic kidney disease patients.

2- It is important to educate the public about $\mathrm{CKD}$, the causes and the importance of social assistance for affected patients. The study also underscores the need for screening, early diagnosis and treatment of patients in order to prevent complications. These measures may help improve the quality of life of CKD patients.

3- There is a need for more studies to assess the QOL of patients in the developing world. It needs to be determined if standardized instruments used in the developed world are applicable and useful in the developing world. It is likely that culturally specific instruments will need to be developed and validated in individual countries.

4- In many countries, providing basic care to sustain life takes precedence over QOL assessments. However, as ESRD care expands and the number of CKD patient's increases, the focus will need to shift from simply prolonging life to providing a better QOL. 


\section{REFERENCES}

Barsoum RS. (2002) : End-stage renal disease in the developing world. Artif Organs;26:737-736

Belasco AG, Sesso R. (2002) : Burden and quality of life of caregivers for haemodialysis patients. Am J Kidney Dis 39: 805-812.

Bremer BA, McCauley CR, Wrona KM,.(1989): Quality of life in end-stage renal disease: A reexamination. Am J Kidney Dis.; 13-.200-209. Abstract MEDLINE

Condé SA, Fernandes N, Santos FR, Chouab A, Mota MM, Bastos MG. (2010):Cognitive decline, depression and quality of life in patients at different stages of chronic kidney disease. J Bras Nefrol;32:242-8

FinkelsteinFQ,Finkelstein SH.(1999): Psychological adaptation and quality of life of the patient with end-stage renal disease. In: Brown $\mathrm{E}$ andParfrey P, eds, Complications of Long Term Dialysis, Oxford University Press, Oxford:; 168-187

FRASURE-SMITH, N, LESPERANCE, F, TALAJIC, M(1996): Depression and 18-month survival after myocardial infarction. Circulation 91:999-1005,

HELD, PJ, PORT, FK, WEBB, RL, (1996): Excerpts from the United States Renal Data System 1996 Annual Report. Am J Kidney Dis 28:S79-S92,

HOUSE, JS, LANDIS, KR, UMBERSON, D(1988): Social relationships and health. Science 241:540-545, PubMed IS! ChemPort

Kalender, B, Ozdemir AC, Dervisoglu, E, Ozdemir O.(2007): Quality of life in chronic kidney disease: effects of treatment modality, depression, malnutrition, and inflammation. Int J Clin Pract.; 61(4): 569-576

Kimmel PL, Peterson RA, Weihs KL, 1995): Aspects of quality of life in hemodialysis patients. J Am Soc Nephrol. 6(5): 1418-1426 
Kimmel PL, Peterson RA, Weihs KL(2000): Multiple measurements of depression predict mortality in a longitudinal study of chronic hemodialysis patients, Kidney In; 57: 2093-2098[1SI][Medline

Levy NB.(1998): Psychology and rehabilitation. In: Daugirdas JT, Ing TS, ed. Handbook of Dialysis, 2nd edition, Little Brown, Boston; 369373

Lowrie EG, Zhang H, LePain N, Lew N, Lazarus JM.(1997) The association of SF-36 quality of life scales with patientmortality. CQI Memorandum, Fresenius Medical Care,

MOOS,.RH \& SCHAEFER, A.T(1984): The crisis of physical illness: An overview and conceptual, approach, in Coping with Physical Illness, edited by MOOS RH, New York, Plenum Medical Publisher, pp 3-25

Moreno F, Lopez Gomez JM, Sanz-Guajardo D, Jofre R, Valderrabano F.(1996): Quality of life in dialysis patients. A Spanish multicentre study. Spanish Cooperative Renal Patients Quality of Life Study Group. Nephrol Dial Transplant. ;11((suppl. 2)):125-9

Mujais SK., Story K, Brouillette J, (2009):et al. Health related quality of life in CKD patients: correlates and evolution over time. Clin J Am Soc Nephrol.; 4(8): 1293-1301

Rambod M, Rafii, F.(2010): Perceived social support and quality of life in Iranian hemodialysis patients. J Nurs Scholarsh; 42(3): 242-249

Rocco MV, Gassman JJ, Wang S, Kaplan RM. (1997): Cross sectional study of quality of life and symptoms in chronic renal disease patients: the modification of diet in renal disease study. Am J Kidney Dis; 29(6): 888-896

RUBERMAN, W, Weinblatt, E, Goldberg, Jd, Chaudhary, BS(1984): Psychosocial influences on mortality after myocardial infarction. N Engl J Med 311:552-559, PubMed ISI ChemPort

Paniagua R, Amato D, Vonesh E, Guo A, Mujais S(2006).: Health-related quality of life predicts outcomes but is not affected by peritoneal clearance: The ADEMEX trial. Kidney Int 67: 1093-1104, 2005 
Sathvik B.S, Parthasarathi G, Narahari M. G, and Gurudev K. C (2008): An assessment of the quality of life in hemodialysis patients using the WHOQOL-BREF questionnaire, Indian J Nephrol. 2008 October; 18(4): $141-9$

US Renal Data System, USRDS (1999): Annual Report, National Institutes of Health, National Institutes of Diabetes and Digestive and Kidney Diseases, Bethesda, Maryland,

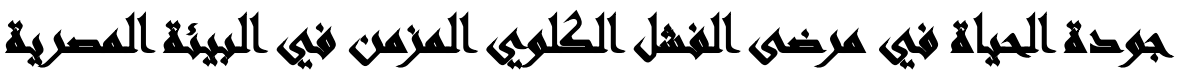

[r]

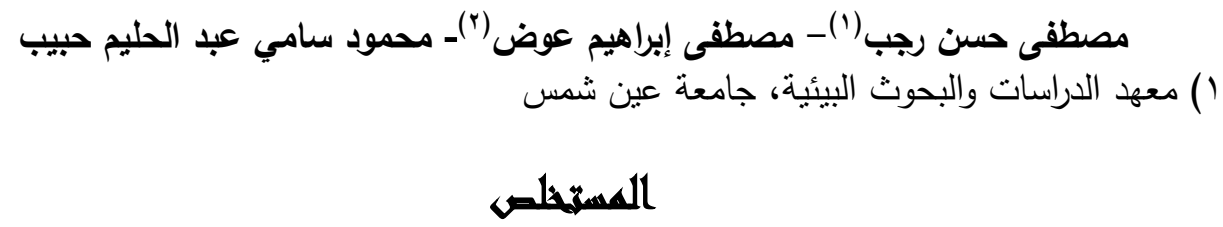

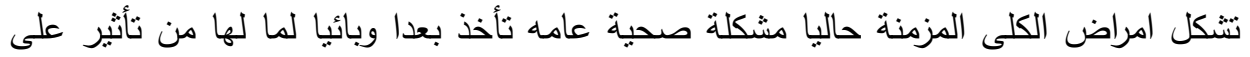

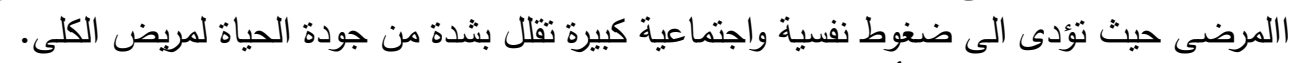

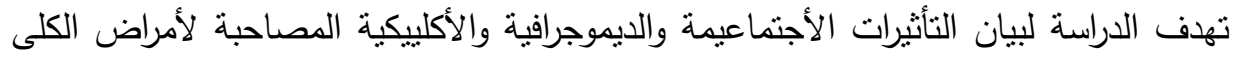

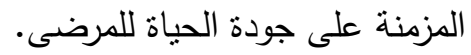

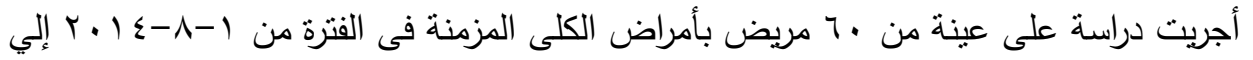

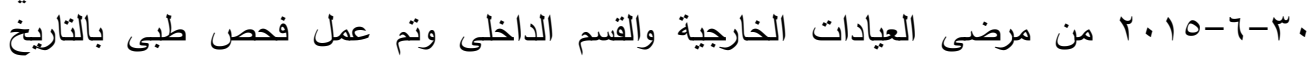
المرضى والكثف الأكلينيكى والأختبارات المعملية ونم اخذ استبيان عن مستوى جودة العيات الحياة بواسطة

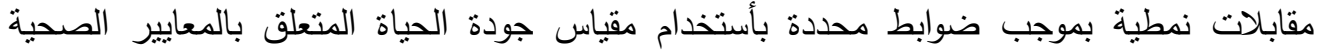

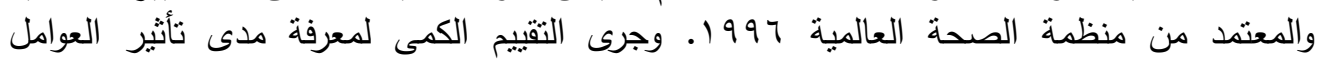

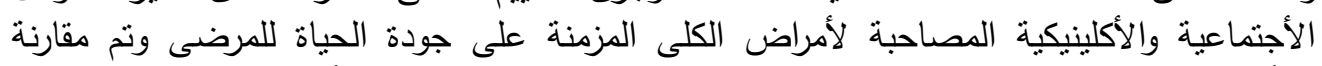

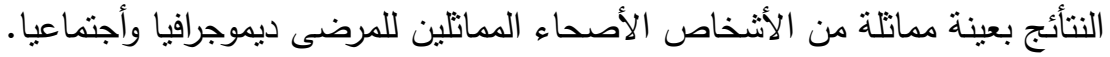

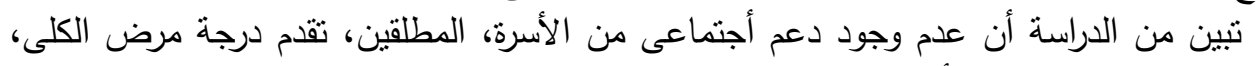

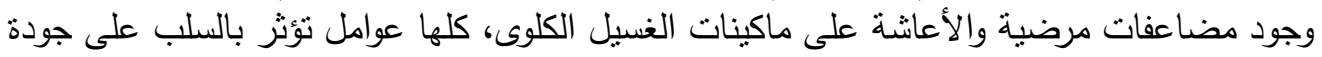

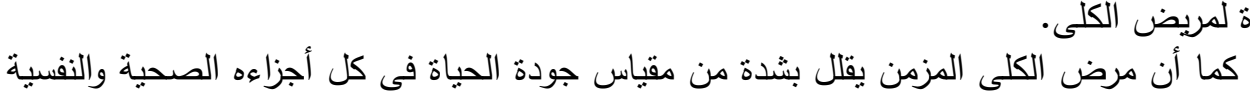

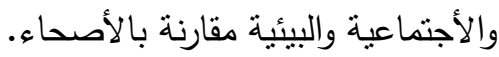

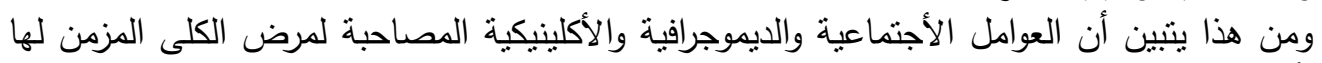

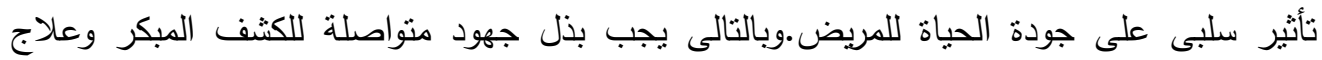


J. Environ. Sci.

Institute of Environmental Studies and Research - Ain Shams University

أمراض الكلى المزمنة مع توفير الدعم النفسي والاجتماعى لمريض الكلى لتخفيف التأثير السلبي لهذه

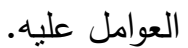

